\title{
Energy Efficiency of Buildings for Various Purposes
}

\author{
Dergunova Anna, Piksaykina Anna, Konin Maksim \\ Federal State Budgetary Educational Institution of Higher Education "National Research Ogarev Mordovia State University", Saransk, Russia
}

Email address:

anna19811981@mail.ru (D. Anna)

\section{To cite this article:}

Dergunova Anna, Piksaykina Anna, Konin Maksim. Energy Efficiency of Buildings for Various Purposes. Journal of Energy, Environmental \& Chemical Engineering. Vol. 4, No. 3, 2019, pp. 34-38. doi: 10.11648/j.jeece.20190403.11

Received: March 28, 2019; Accepted: May 10, 2019; Published: October 21, 2019

\begin{abstract}
The construction industry is the largest consumer of material and energy resources. Resource saving makes a great contribution to energy, environmental security and improving the quality of life of the population - the constituent elements of national security. An important part of resource saving is improving the energy efficiency of buildings. The problem of energy efficiency has been relevant for more than fifty years. Energy-efficient buildings must meet the requirements of minimum energy consumption not only at the design stage, but in general throughout the life cycle, which includes the processes of design, construction and installation works, construction control, operation and disposal. Improving of the energy efficiency of buildings is the process of bringing the design of the total reduced costs of external walling and heating of the building to the minimum possible value. The main elements of the operating costs for heating the building are fuel costs. Therefore, the optimization of the level of thermal protection of buildings will not only increase the level of energy efficiency and comfort of civil buildings, but also provide a significant economic effect, the value of which will continuously increase in accordance with the life of the building. The method of optimizing the level of energy efficiency, including thermal protection of buildings for various purposes, should help to improve the balance of wall materials and structures, so that the production of the most costeffective products continuously increases and, accordingly, the share in the balance of less economical products decreases. As a result of this restructuring of the building materials industry can get a significant economic effect. Thus, there is a link between the level of thermal comfort of civil and industrial buildings and the increase in productivity, the reduction in the number of diseases of workers, the reduction of the corresponding costs of production and health care and, ultimately, the growth of national income.
\end{abstract}

Keywords: Energy Efficiency, Thermal Protection of Buildings, Comfort of Buildings, Economic Effect, Social Effect

\section{Introduction}

The concept of "Energy-efficient building" exists in construction science for about 50 years, and throughout this period of time, interest in these buildings has not been lost, and the problem of ensuring energy efficiency is modern and relevant. During this time, besides the term "energy-efficient building", such as "passive buildings", "energy-active buildings", "green buildings" and many others have appeared.

Energy-efficient buildings for the half-century history of their appearance have undergone a significant evolution from the appearance of the first principles of insulation of external enclosing structures to complete synthesis with the environment, awareness of the need for sustainable development, harmony with man, economy and efficient use of not only energy, but also other types of resources. It becomes obvious that energy-efficient buildings must meet the requirements of minimum energy consumption not only at the design stage, but in general throughout the life cycle, which includes the design processes, construction and installation, construction control, operation and disposal (dismantling). At the same time, energy-efficient buildings must meet the requirements of safety and reliability, as well as provide the necessary consumer level of comfort with regulatory or lower energy costs throughout the entire life cycle.

There are various understandings of energy efficient buildings [1-7]. Some scientists determine the energy efficiency of a building as a property of an object and its engineering systems to ensure a given level of heat energy consumption to maintain optimal parameters of the indoor microclimate [3], others like a building with energy 
consumption indicators lower than those established by standards [4]. The energy efficiency of a building is defined as a property of an object and its engineering systems to ensure a given level of heat energy consumption to maintain optimal parameters of the indoor microclimate [6].

An integral part of the energy efficiency of buildings is their thermal efficiency. The thermal efficiency of a building is determined by a set of architectural, design-planning and engineering solutions that provide normalized thermal and air conditions in the premises at certain costs of thermal energy.

Over the years, many specialists worked on the problem of the thermal efficiency of buildings, among which should be noted scientists engaged in the economic justification for increasing thermal efficiency [8-20].

The interest in this problem is explained by the fact that as a result of optimization of the heat protection level of buildings, many of the tasks facing country can be solved more successfully, such as improving the comfort level of civil buildings, reducing the cost of operating buildings for various purposes, reducing fuel consumption, increasing labor productivity, etc.

\section{The Characteristics of the Object}

The improving the energy efficiency of buildings is the process of bringing the total reduced costs for external building envelopes and heating to the smallest possible value during designing.

However, optimizing the level of energy efficiency of buildings brings not only an economic effect. At the same time, it ensures a rise in the level of thermal comfort in the premises and a corresponding social effect, as well as a saving of the top-life. In industrial agricultural buildings, the optimization of the level of their energy efficiency increases the productivity of livestock and poultry farming and ensures the preservation of buildings. Therefore, this event contributes to the solution of a number of problems facing the economy of country at the present time.

Increasing the level of comfort of civil buildings is not possible when the premises are not provided with a sufficiently high level of thermal comfort. The level of comfort as higher as higher the temperature of the inner surface of the outer enclosing structures $\left(\tau_{\text {int }}\right)$ (external walls, filling of light apertures, coatings, etc.).

The dimension $\tau_{\text {int }}$ depends on the heat transfer resistance $\mathrm{R}_{0}$ of the corresponding design. This dependence is determined in $\mathrm{W} / \mathrm{m}^{2}$ by the formula [8]

$$
\begin{gathered}
Q=\frac{t_{\text {int }}-t_{\text {ext }}}{R_{0}}=\frac{t_{\text {int }}-\tau_{\text {int }}}{R_{\text {int }}} \\
\tau_{\text {int }}=t_{\text {int }}-\frac{R_{\text {int }}}{R_{0}}\left(t_{\text {int }}-t_{\text {ext }}\right)
\end{gathered}
$$

Where $\mathrm{Q}$ is the calculated heat loss through the enclosing structure, $t_{\text {int }}$ is the design temperature of the internal air, $t_{\text {ext }}$ is the design winter outdoor temperature, $R_{\text {int }}$ is the heat transfer resistance of the internal surface of the enclosing structure.

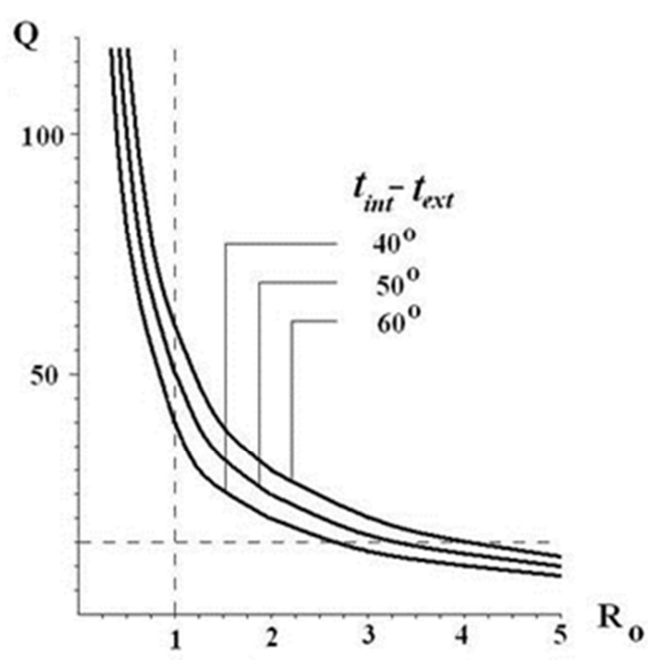

Figure 1. Curves of changes in the specific heat flux $Q$ depending on the total heat transfer resistance of the fence $R 0$ for the modules of the difference between the temperatures of the external and internal air of the room at 40, $50,60^{\circ} \mathrm{C}$.

It can be seen that the boundary passes along the rapidly changing side of the hyperbola and relatively large values of the specific heat flux Q. Consequently, the heat transfer resistance values are on the order of a unit for brick and panel walls of buildings built 20-50 years ago in Irkutsk and still in operation, to the least extent meet modern ideas about the thermal insulation properties of wall fences and thermal protection of buildings.

In the section $\mathrm{R}_{0}>2$, the rate of change of specific heat flux decreases, for example, for a curve with a temperature difference of $50^{\circ} \mathrm{C}$, the flux values are successively $25,16.6$, $12.5,10 \mathrm{~W} / \mathrm{m}^{2}$ for heat transfer resistance values of $2,3,4$ and 5, respectively.

Analysis of the rate of change of the specific heat flux allows us to draw another boundary on the graph that separates the rapid changes in the heat flux from the slow ones, for example, less than $15 \mathrm{~W} / \mathrm{m} 2$. This threshold value of the specific heat flux, averaged over all enclosing structures, can be considered the upper quantitative estimate for buildings, which make it possible to classify them as energy-efficient. Given in figure 1 chart makes it possible to understand the principles of increasing the thermal protection of buildings, related to the determination of the optimal value of the total resistance to heat transfer of enclosing structures. It can be seen that the values of specific heat flux for $\mathrm{R}_{0}>5$ change insignificantly and a further increase in the total resistance to heat transfer does not lead to an almost noticeable decrease in heat loss. It should also be noted that sufficiently large $\mathrm{R}_{0}$ values and very small total heat losses can lead to a noticeable decrease in the entire thermal stability of the building, since heat flows through windows, doors and losses due to external air infiltration will dominate the balance of heat losses in individual rooms.

Under specific design conditions, the temperature of the inner surface of the outer enclosing structures depends only on the heat transfer resistance of the inner surface of the 
enclosing structure; all other factors are constant under these conditions. Consequently, two variants of some external enclosing structure with different values of the heat transfer resistance correlate to the inner surface of the enclosing structure, then not only the total reduced costs for this construction and heating of the building, but also the level of thermal comfort in its premises.

Proceeding from the need to create thermal comfort, hygienists require that the normalized temperature difference between the internal air and the internal surface of the outer envelope $\Delta \mathrm{t}_{\mathrm{ext}}=\mathrm{t}_{\mathrm{nt}}-\tau_{\mathrm{int}}$ should not exceed $3-4^{\circ} \mathrm{C}$. However, at present, this temperature difference is set at $6^{\circ} \mathrm{C}$ for residential premises, hospitals, schools, polyclinics and kindergartens, and $7^{\circ} \mathrm{C}$ for other public and administrative buildings. It is obvious that with such a large difference in temperature in the buildings of the listed buildings, proper thermal comfort cannot be ensured.

It should be noted that with a high value of the temperature difference, the second requirement is not applied to the external enclosing structures (and taken into account when setting this value)-a guarantee from the condensation of water vapor on the inner surface of the structure: its humidity, which is often found in construction practice. Humidification of walls and coverings (attic overlapping) leads to acceleration of the process of degassing the wall or overlapping.

At low temperatures of the inner surface of the outer enclosing structures of livestock and poultry houses, there is a sharp decrease in milk yield, egg production and weight gain, with an increase in feed consumption and a decrease in the safety of animal feed. Often in such cases, the excessive thermal radiation of animals on the cold inner surface of the cover can't be compensated for by the production of additional heat by the animals, and then "combustion" begins in the body of the scarcest nutrients-animal proteins.

\section{Apparatus and Methods of Measuring}

Currently, when designing external building envelope structures, often proceed from the minimum allowable resistance to heat transfer, i. e. take the option with the lowest building cost and the maximum operational costs. This practice of projecting completely contradicts the generally accepted requirement-to identify and accept in projects only the option that provides the least expenditure, i. e. the best option.

This option of thermal protection of the building, is determined by the formula

$$
R_{t}=R_{w}^{u n} f_{w}+R_{l}^{u n} f_{l}+R_{c}^{u n} f_{c}=\text { minimum }
$$

where $R_{t}$ is the total reduced costs for external enclosing structures and building heating; $R_{w}^{u n}, R_{l}^{u n}, R_{c}^{u n}$ are the specific reduced costs for external walls, filling the light apertures and covering buildings, dollar $/ \mathrm{m}^{2}$ of structures; $f_{w}, f_{l}, f_{c}$-total areas of the corresponding building envelope, $\mathrm{m}^{2}$.

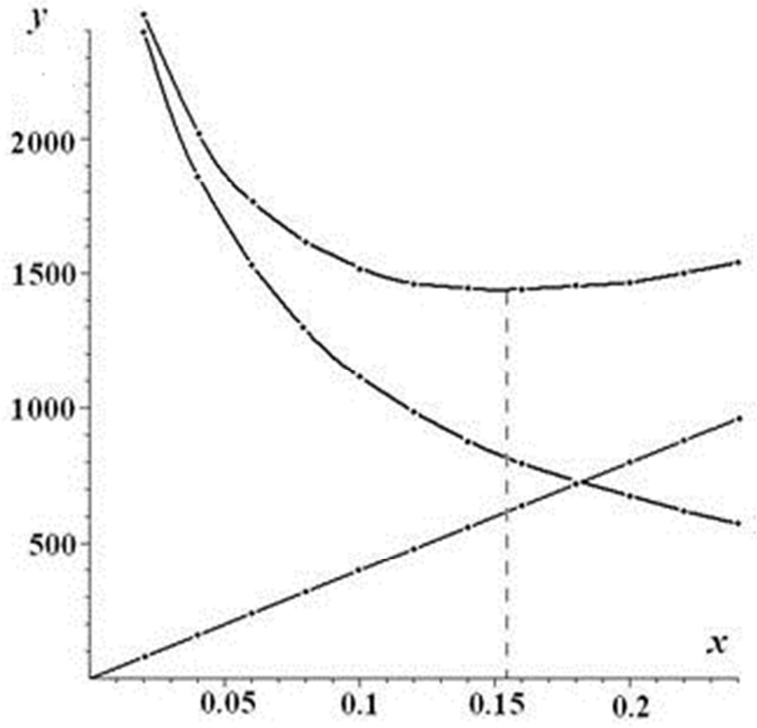

Figure 2. The results of the graphic calculation of the cost of additional insulation using the method of minimizing the cost of service life:(a) total costs in 10 years; (b) the cost of thermal insulation and its installation; (c) heating costs for 10 years.

Obviously, costs can be minimal only when each term is minimal. Reducing the specific resulted costs for external fencing structures is achieved by identifying and implementing the most economically feasible options. Reduction of the total areas of these structures achieve the perfection of architectural and space-planning solutions of the corresponding buildings

The main elements of the operating costs for heating the building is the cost of fuel, and when supplying the heating system with heat from the CHP plant-the cost of this heat. Therefore, the optimization of the level of thermal protection of buildings will not only increase the level of energy efficiency and comfort of civil buildings, but will also provide a significant economic effect, the magnitude of which will increase continuously in accordance with the operational lifetime of the building.

If we compare the indicated values of the resistance to the heat transfer of the enclosing structures in Sweden to those required by the building codes in Moscow [22], then it turns out that with all other conditions being equal, the heat costs for the heating of Moscow buildings are more than double the same costs in Sweden. The heat saving is additionally increased due to the presence in the "conditions" of the requirements for automatic regulation of the air temperature in the building's premises and about the equipment of the devices for the regeneration of the heat of the exhaust ventilation systems. The types of residential buildings, their landscaping, number of floors, used materials and products, technology and organization of construction have changed.

When determining energy efficiency, it is necessary to take into account a number of factors, which include: the need to take into account capital investments and operating costs not only for the heating system of buildings, but also for other elements of the heat supply system-boiler houses (or thermal 
power plants) and thermal external networks; a change in the procedure for determining the operating costs for thermal energy; when building a building in a developed settlement, they are usually taken in accordance with the established selling price; in the new city it is not known, and these costs are determined as the sum of the individual elements; the cost of fuel should be determined not at the price list, but based on the closing costs of fuel, as a change in the volume of its consumption can be very significant and require the commissioning of new, less economically expedient fuel deposits; the cost price of the panels of external walls and coatings is defined differently than small-sized materials,-the cost of the panel increases with its thickness more slowly than the thickness. It should also be taken into account in capital investments additional costs for partial reconstruction of the prefabricated plant; it is necessary to take into account the influence of this measure on the prospects of development of related industries-the construction materials industry (the demand for cement, expanded clay, effective heat-insulating materials, etc.) and fuel-extracting industry will increase (fuel consumption for heating buildings decreases). This account is necessary for the timely introduction of appropriate adjustments to the plans for the long-term development of these sectors of the economy; design conditions require the determination of the area of economically expedient use of manufactured building materials, the use of which in panels of external walls and coatings is currently possible in the near future; the identification of the field of application of these materials is necessary to determine the total demand for them, and the cost of construction also depends on it.

In the methodology of optimizing the level of energy efficiency, including thermal protection of buildings, it is necessary to find ways to take into account the additional effect, which currently does not have a quantitative evaluation, of the effect of increasing the level of thermal comfort. It was previously indicated that this issue, especially important for civilian buildings, has not yet been resolved. All the tasks of comparing project solutions in these buildings can be divided into three groups:

a) providing the same level of comfort (for example, variants of interstitial overlap or partitions, providing the same level of sound insulation);

b) envisaging for an increased level of comfort (for example, increasing the height of rooms or kitchen areas, etc.). In such cases, usually capital investments and operating costs increase. Therefore, the increase in the level of comfort cannot be quantified, and additional capital investments in advance plan accordingly increase the funds allocated to the construction of non-production facilities;

c) ensuring an increasing of the level of thermal comfort, both simultaneously reduce the reduced costs, and not taken into account the quantitative social effect. Therefore, their effectiveness is higher than in point a.

\section{The Results of the Measurements}

The methodology for optimizing the level of energy efficiency, including thermal protection of buildings for various purposes, should help improve the balance of wall materials and structures in our country so that the output of economically most efficient products increases continuously and accordingly the share in the balance sheet is reduced less economical. As a result of such a restructuring of the building materials industry, a significant economic effect can be obtained.

The social effect in improving the energy efficiency of buildings is the result of an increasing in the level of thermal comfort in their premises. Hygienists define this comfort as a physiological condition in which the central nervous system receives the least amount of external stimuli that indicate changes in the environment, and the mechanisms of thermoregulation (the vascular system) experience the least irritation. With such a physiological state, the organism's forces recovering most violently during the productive activity of people are most fully recovered, which ensures the high productivity of their labor. After the residence of people in the rooms with a low level of thermal comfort, the production of their labor decreases. Doctors-hygienists have established that people living in buildings whose external enclosing structures have relatively little resistance to heat transfer are more likely to suffer from cold and neuralgic diseases and lesions of the peripheral nervous system than those living in buildings that are warmer and moderately glazed. Thermal comfort of the wall, the more it reflects in the position of infrared heat rays. With a low temperature wall, it absorbs heat rays intensively and as a result, the heat radiation from the part of the body of the person facing the wall, this radiation is especially dramatic when there is a large area of a window opening with one or two layers of glass in the room. With such windows, a person in a room with a normal temperature of the air, it feels cold currents and can be sick, as with one-sided cooling of the organism its thermal control processes are violated. At the same time the infiltration of the outside air through the inaccessibility in the fillings increases, this contributes to the formation of temperature gradients fields inside the buildings. Calculations showed that in Moscow conditions, with windows with paired binders, thermal comfort at a distance of $1 \mathrm{~m}$ from the window is possible only in those cases when its area does not exceed $25-35 \%$ of the total area of the outer fences.

\section{Conclusions}

There is no doubt that there is a connection between the level of thermal comfort of civil and industrial buildings and the growth of labor productivity, a reduction in the number of diseases of workers, a reduction in the corresponding costs of production and health, and, ultimately, an increase in national income.

We can offer the following most efficient energy-saving measures in the systems of heat and power supply and airconditioning of buildings, characteristic of the current stage of development of the construction industry in the construction and reconstruction of buildings: a change in the 
centralized heat supply scheme associated with the rejection of the use of central heating units and the introduction of individual heating units, as a result of which it is possible to regulate and account for heat consumption at each specific facility;

i. a change in the centralized heat supply scheme associated with the rejection of the use of central heating units and the introduction of individual heating units, as a result of which it is possible to regulate and account for heat consumption at each specific facility;

ii. regulation of heat consumption on a separate heating device, taking into account the actual thermal balance of the room;

iii. the use of periodic heating-lowering the internal air temperature below the standard value during part of the day, allowed in a number of buildings (schools, theaters, etc.);

iv. reducing energy costs for heating ventilation air while improving the quality of the microclimate through the use of new ventilation systems.

\section{References}

[1] Golubtsov N. In., Efremov L. G., Hismatullin R. G. The energy efficiency of buildings and structures in the aspect of lifecycle management. Bulletin of the Chuvash University. 2013. 11, pp. 247-255.

[2] Gorshkov A. S., Rymkevich P. P., Nemova D. V. Saving or not? Russian energy saving requirements/ Energy Saving. 2014. 2, pp. 26-32.

[3] Matrosov, Y. A. Regulatory framework of energy efficiency in buildings at the Federal and regional levels. Heat and power efficient technology. Newsletter. 2003. 4, pp. 28-33.

[4] Oparina, L. A. Definition of the term "energy-efficient building". Housing construction. 2010. 8, pp. 2-4.

[5] Prokhorov V. I. Operating costs of energy, energy balance of engineering systems of the building and payback of new energy-saving solutions. Theoretical bases of heat and gas supply and ventilation. Third international scientific and technical conference: collection of reports. Moscow, MGSU, 2009, pp. 30-32.

[6] Tabunschikov, Yu. A., Brodach M. M., Shilkin N. In. Energy Efficient buildings. Moscow, AVOK-PRESS, 2003.

[7] Tsygankov V. M. Energy Efficiency. Russian Specifics. Energy saving. 2016. 4, pp. 28-33.

[8] Bogoslovsky V. N. Building Thermophysics (thermo-physical fundamentals of heating, ventilation and air conditioning). V. N. Theological. St. Petersburg: ed. AVOK Severo-Zapad, 2006.
[9] Brodach M. M., Shilkin N. B. Optimization of thermal efficiency of buildings. Walls and facades. Actual problems of Thermophysics. Moscow. 2003. P. 191-196.

[10] Gagarin V. G. Macroeconomic aspects of justification of power saving up actions at increase of thermal protection of the protecting designs of buildings. Building materials. 2010. 3 , pp. 8-16.

[11] Gorshkov A. S, Muravyev P. A., Taraskin A. V. Increasing the level of insulation of the outer walls of a low-rise building. Energy Saving. 2016. 8, pp. 31-34.

[12] Gorshkov A. S, Heat Engineering Characteristics of Building Envelopes. Part 2. Russian Rating Principles. Energy Saving. 2017. 8, pp. $45-50$.

[13] Tolstova Yu. I., Mikholap M. A., Komkova M. G. Optimization of thermal protection of buildings. Theoretical bases of heat and gas supply and ventilation. Fifth international scientific and technical conference: collection of reports. Moscow: MGSU, 2013. pp. 78-83.

[14] Belyaev V. S., Granik Yu. G., Matrosov Yu. A "Energy Efficiency and Building Heat Protection". Publishing Association of Construction Universities, 2014.

[15] Kornienko S. V. Integrated assessment of energy efficiency and thermal protection of buildings. Construction of unique buildings and structures. 2014. 11 (26), pp. 33-48.

[16] Stakhov A. E. Kazakova S. Yu. Andrienko A. A. Evaluation of design solutions for thermal protection of buildings by economic methods. Bulletin of civil engineers. 2018. 3 (68), pp. 219-222.

[17] Batting N. I., Nemova D. V., Rymkevich P. P., Gorshkov A. S. the Influence of the level of thermal protection of enclosing structures on the amount of heat losses in the building. Civil Engineering journal. 2012. 8, pp. 4-14.

[18] Krivoshein A. D., Fedorov S. V. On the calculation of the reduced resistance to heat transfer of enclosing structures //civil Engineering journal. 2010. No. 8. P. 21-27.

[19] Greenfeld G. I. Dialectics of normative requirements to resistance to heat transfer of enclosing structures. Housing construction. 2012. 1, pp. 22-24.

[20] Al-Homoud M. S. A systematic approach for the thermal design optimization of building envelopes. Journal of building physics. 2005. Vol. 29, 2, pp. 95-119.

[21] Moncef K. Energy audit of building systems: an engineering approach. Boca Raton: CRC Press, 2011.

[22] SNiP 23-02-20032 "Thermal protection of buildings". 